\title{
EL ARTE COLONIAL EN CINCO CIUDADES DE MEXICO
}

\section{Por Elisa Vargas Lugo}

En el importante conjunto que forman los libros y artículos escritos por el doctor Francisco de la Maza, a lo largo de su brillante carrera profesional, figuran seis estudios monográficos relacionados especialmente con cinco ciudades del país: México, Zacatecas, Durango, San Miguel de Allende y San Luis Potosí. Por su contenido constituyen -aunque no todos sean monografías artísticas - contribuciones muy importantes para el conocimiento del arte colonial. Deben considerarse también estos estudios, por su alta calidad académica, como base para cualquier investigación que en el futuro se pretenda hacer sobre esta etapa del arte mexicano. Frutos de distintos tiempos de la vida del maestro, los mencionados trabajos presentan diferentes enfoques y caracteristicas entre sí. No están estructurados dentro de un plan preconcebido de trabajo seriado, sino que cada uno es respuesta a una motivación personal, circunstancial, que alentó su espíritu -siempre aprestado a informar y luchar por el arte colonial- en un momento dado. Dos de dichas obras son monografías históricas de ciudades dentro de las cuales queda comprendido el estudio del arte, como parte del desarrollo cultural del lugar. Tres más son monografías artísticas pero -como era lógico en este caso- circunscritas al arte colonial de una población y las referencias históricas se hacen solamente en función de la actividad artística. Por último encontramos una monografía sobre un elemento artístico: el apoyo estípite y su floración en la ciudad de México. Dichos estudios por orden cronológico de aparición, son:

1. San Miguel de Allende. Su historia. Sus monumentos. México, UNAM, 1939. Este libro con ilustraciones y 215 páginas de texto tiene el especial interés de haber sido la tesis profesional de Francisco de la Maza para obtener el grado de Maestro. Dentro de tal género, es decir como tesis de historia fue un trabajo novedoso -además de meritorio- por dedicar muchas de sus páginas al estudio del arte colonial que se produjo en esa población guanajuatense. Esta innovación revela no sólo la temprana y decidida inclinación del autor por los estudios del arte, sino también su tendencia hacia un sano historicismo. Así, un poco a imagen y semejanza de su maestro don Manuel Toussaint -quien hacia pocos años había publicado una monografía histórico-artística sobre Taxco-el 
entonces joven De la Maza, escribió la historia de San Miguel de Allende ubicando debidamente las obras de arte como parte integrante del concierto histórico del lugar. Cronológicamente el libro abarca desde los antecedentes prehispánicos de la zona y la fundación de la actual ciudad por Fray Juan de San Miguel, en 1542, hasta los principales acontecimientos del primer cuarto de este siglo. Es muy interesante la tesis que presenta sobre la gran importancia de la personalidad de don Ignacio Allende frente a la de don Miguel Hidalgo. Por lo que respecta al arte colonial, que es lo que me interesa destacar, De la Maza aportó con este libro nada menos que la primera y única visión de conjunto que existe del arte novohispano sanmigueleño hasta la fecha, aunque, como lo dijo don Manuel Toussaint en la introducción del libro, la parte correspondiente a la arquitectura civil -que es una de las más ricas y diferenciadas que podemos encontrar en todo el país- es bastante floja.

Como apéndice del libro hay un interesante estudio sobre el Santuario de Atotonilco y la obra pictórica y arquitectónica que allí creó el padre Alfaro.

2. En 1947 el maestro Francisco de la Maza asistió como delegado del Instituto de Investigaciones Estéticas al VIII Congreso de Historia celebrado en la ciudad de Durango. Aprovechó su estancia en dicha población para estudiar su arte colonial, y poco después completó sus observaciones con las investigaciones históricas necesarias y elaboró un trabajo titulado: La ciudad de Durango. Notas de arte que, auspiciado por la Sociedad de Geografía y Estadística, vio la luz en México el año de 1948. Éste, un pequeño libro de 30 páginas con sus correspondientes ilustraciones, que no se ocupa, como en el caso anterior, de la historia político-social local, sino únicamente del estudio formal de los edificios durangueños del periodo novohispano, constituyó una gran aportación en este campo pues por primera vez señaló las caracterfsticas, novedades formales y valores del arte de la ciudad de Durango y dio a conocer monumentos prácticamente desconocidos para todos.

3. La conocida revista México en el Arte dedicó su número 7 en homenaje al gran poeta Ramón López Velarde, en el año de 1949. De la Maza, invitado a colaborar escribió un precioso artículo de 13 páginas, ilustrado, titulado: "El Arte en la Ciudad de Nuestra Señora de los Zacatecas." Mediante las indispensables referencias históricas, el autor informa y analiza, igual que en la obra anterior, los monumentos de 
arte colonial construidos en esa población minera. El título del artículo no se cumple totalmente porque sucede casi lo mismo que en el libro sobre San Miguel de Allende; que el autor dice muy poco de la arquitectura civil, que en ambos casos hubiera merecido mayor atención. Como obra aislada el artículo muestra un gran avance erudito y estilístico respecto a las publicaciones anteriores y es notable por su calidad literaria; sin duda alguna pertenece a las mejores páginas de la prosa compuesta por el ilustre desaparecido. Como información artística fue una novedad en gran parte y sobre todo tiene el mérito de ofrecer una visión de conjunto de los monumentos zacatecanos, no hecha hasta entonces.

4. La ciudad de México en el siglo XVI, es el título de un pequeño libro de 65 páginas, ilustrado, publicado en 1968 por el Fondo de Cultura Económica. El autor, basándose en los textos originales de la época, comenta y revive con sabidurfa y agudeza diferentes aspectos de la vida capitalina de aquel entonces, concediendo desde luego, importantes párrafos a considerar la actividad artf́stica. Se trata de una resumida y amena revisión histórica, una especie de guía para hacer una visita al pasado, dentro de la cual el arte ocupa el lugar que le corresponde al lado de las otras manifestaciones sociales, vitales. Tiene esta obra el atractivo de presentar al lector un intento de recreación del aspecto urbano que debió lucir la capital en el siglo xvir, de la apariencia que debian haber tenido sus edificios civiles y religiosos. Todo esto animado con las historias de los personajes notables del tiempo, las diversiones, las castas, en fin, el hombre que vivió aquella ciudad.

5. La misma editorial, Fondo de Cultura Económica, publicó al año siguiente, o sea en 1969, otra breve pero muy importante obra de Francisco de la Maza: El churrigueresco en la ciudad de México, que consta de 68 páginas con sus respectivas ilustraciones. Fundamentalmente este estudio es un sabio resumen sumamente útil, acerca del origen y sentido formal del apoyo estípite asf como de la modalidad barroca del mismo nombre. Habla de la aparición del estípite en España y de su florecimiento en nuestra capital. Es además una revisión exhaustiva de las obras estípites que se encuentran en la ciudad de México con importantes noticias sobre la construcción de templos y retablos y de algunos de sus arquitectos. Constituye por ende un manual indispensable para cualquier estudioso del arte colonial. 
6. Una de las últimas obras escritas por el doctor De la Maza fue la monografía artística, dedicada con especial empeño al arte que se produjo en su tierra natal durante la etapa novohispana. Se trata de un libro de 87 páginas, de formato grande, espléndidamente ilustrado, que lleva el siguiente título: El arte colonial en San Luis Potosi, publicado por el Instituto de Investigaciones Estéticas de la UNAM, también en 1969. Con ejemplar entusiasmo el autor se entregó a revisar y analizar exhaustivamente el arte colonial existente en dicha ciudad y aun el ya desaparecido. Apoyándose en cada caso sobre importantes informaciones históricas -obtenidas de crónicas y archivos- proporciona numerosas noticias acerca de cómo fueron las plazas, los templos, los conventos y demás edificios de San Luis Potosí. Ofrece así un inapreciable trabajo de conjunto que permite imaginarse la ciudad potosina en todo su esplendor barroco. Fue tal su preocupación por dejar registrado en su libro todas las obras de arte coloniales, que éste, al mismo tiempo que es un estudio formal comentado, resulta un magnifico inventario.

Se puede decir que todo lo que escribió Francisco de la Maza -n mayor o menor grado- tiene la alta calidad literaria que la crítica reconoce en su amena prosa tan espontánea y ágil. Sólo deseo señalar que en el grupo de obras mencionadas es fácil apreciar un cambio, en este aspecto, como es lógico, entre sus obras de juventud, tales como San Miguel de Allende y La ciudad de Durango, y las más recientes publicaciones. A partir del artículo que escribió sobre la ciudad de Zacatecas, la prosa del autor puede considerarse ya madura, su estilo personal ya definido; rica y barroca expresión de su espíritu. En particular dicho artículo sobre Zacatecas, repito, es uno de los escritos de mayor fluidez y belleza que nos dejó el autor. La introducción de éste, así como la del libro sobre San Luis Potosí deben leerse como parte de sus mejores creaciones literarias.

\section{NUEVOS ARTISTAS Y ATRIBUCIONES}

Francisco de la Maza supo ser también un severo erudito y esta disciplina bien manejada fortalece las informaciones que nos da sobre los monumentos de las ciudades que estudia. Los nombres de los patronos fundadores, de los frailes directores y cuando es posible de los artistas creadores, aparecen al lado de las obras reseñadas entre doctos y agudos comentarios. Todos los especialistas saben la enorme dificultad que hay - por falta de documentación- para localizar la identidad de los artis- 
tas, aun de aquellos que crearon obras de primera importancia, por ello resulta tan valiosa cualquiera aportación en este sentido, cualquier nombre nuevo, aunque sea de segundo orden, que podamos ir añadiendo a la nómina de artistas novohispanos. El doctor De la Maza dejó en sus obras varias adiciones y aclaraciones en este campo, de las cuales menciono algunas a continuación.

Hasta donde hemos podido averiguar fue en su libro sobre San Miguel de Allende, donde Francisco de la Maza dio a conocer el nombre del maestro cantero, sanmigueleño, que construyó audazmente la fachada gotizante de la parroquia del lugar: don Zeferino Gutiérrez informándonos además de alguna otra obra que le es atribuible. Por otra parte, al ocuparse de la hermosa portada estípite del templo de San Francisco, no está de acuerdo con el Dr. Atl en pensar que el autor haya sido el arquitecto andaluz Lorenzo Rodríguez; si bien le parece posible, claramente y con toda razón, piensa que sin documentos a la mano es temerario apoyar tal atribución. En cambio considera que esta obra y la portada de la iglesia de Dolores Hidalgo -población cercana a la de San Miguel- son de la misma mano y que ambas están relacionadas formalmente con la fachada de Valenciana, 1 cosa que no ha sido confirmada por ningún estudio posterior.

En su libro sobre Durango, De la Maza habla ampliamente de la catedral y sus características formales, comentando que Pedro de las Huertas, autor de las barrocas y ricas portadas laterales, hizo en ellas gala de imaginación desbordante, por lo cual además de que da a conocer su nombre, le atribuye la paternidad del Palacio Suchil obra construida entre 1760-1770, 2 que es el edificio más importante de la arquitectura civil novohispana de dicha ciudad. En el mismo estudio hace destacar con énfasis la existencia de pinturas salidas del pincel de los artistas Juan Correa, Juan de Aguilera, Antonio de Torres, Luis Juárez, etcétera, lo que en su tiempo fue una gran contribución al conocimiento de la pintura colonial, todavia hoy tan mal estudiada.

En su libro sobre San Luis Potosi, por ser una obra de mayor extensión y de análisis muy minucioso de las obras, el autor proporciona numerosas noticias de primer orden.

1 Francisco de la Maza, San Miguel de Allende, p. 63. México, UNAM, 1939. Acaba de aparecer la segunda edición de esta obra, publicada por el Frente de Afirmación Hispanista, A. C., en la ciudad de México en 1972, con un apéndice prehispánico por Miguel S. Malo Zoraya.

2 La Ciudad de Durango. Notas de Arte, p. 23. México, Imprenta "Grama”, 1948. 3 Ibidem, p. 26. 
La historia de la edificación del Palacio de Gobierno es una de ellas. Comienza la información a partir del primitivo edificio de adobe, con pequeños datos acerca de las vicisitudes en que se vio envuelta la construcción y destaca -terminando con la confusión imperante al respectoel nombre del conocido arquitecto Miguel Costanzó como creador de los planos fundamentales, que fueron ejecutados por otro arquitecto de apellido Pérez. Proporciona también nombres de canteros y herreros y aclara finalmente, que en la terminación del edificio no intervino Felipe Cleere -artista potosino- como se crela generalmente, sino que fue el alarife Juan Bautista Crouzet, autor de la catedral de Monterrey, quien terminó la obra.

Hace resaltar la originalidad del plano de Costanzó quien en vez de colocar una sola grandiosa escalera al fondo de la entrada, colocó dos, una a cada lado de la puerta, coronadas con cúpulas ochavadas. ${ }^{4}$

Muy importante sin embargo, resultó para la ciudad natal de De la Maza la actividad de Felipe Cleere a quien dedica buenos párrafos.

La trayectoria arquitectónica de Felipe Cleere -noa dice- artista no tomado en cuenta hasta ahora en las histotrias de Arte Colonial, es consecuente y precisa con su época. Primero en la Real Caja (1760-1770) es un artista barroco, mesurado y tradicional con la arquitectura potosina, pero muy personal y con detalles novedosos. Luego en el Santuario [de Guadalupe] es más barroco y audaz, pero a la vez, más ecléctico, construyendo una obra original pero muy discutible (1770-1780). Después, en 1790-1800, en la Alhóndiga de Zacatecas, es ya una arquitecto neoclásico. ${ }^{\circ}$

Sobre la construcción de la Alhóndiga potosina -obra hecha entre 1771 y 1777-, informa que se siguieron los planos del capitán Pedro Román Fernández, encargándose de la obra Manuel de la Sierra."

Una de las obras más bellas y estimadas de San Luis Potosi, como es sabido, es la Caja de Agua que generalmente se atribuye a Tresguerras, el conocido artista celayense, pero que según el bistoriador potosino Meade, fue obra de un artista decorador, de Morelia, de apellido Zapari. De la Maza concluye al respecto que aunque lo más probable es que Tresguerras tenga la paternidad de la obra, no se puede afirmar nada sin tener a la mano la adecuada documentación, por lo que la Caja de Agua, ... sigue siendo anónima. ${ }^{\top}$

1 Francisco de la Maza, El arte colonial en San Luis Potosí, pp. 25-29. México, UNAM, 1969.

6 lbidem, p. 70.

Ibidem, p. 94.

7 Ibidem, pp. 32-39. 
Hace notar la importancia del cronista Arlegui en relación con la historia de varios edificios coloniales potosinos y destaca su directa intervención en la construcción de la Capilla de los Remedios o del Sagrado Corazón, como se la conoce hoy. ${ }^{8}$

De la Maza, según decíamos, emprendió la difícil y cansada tarea de registrar todas las dependencias de los edificios potosinos que estudiaba, así, este libro es como un inventario en el cual las obras pictóricas han sido anotadas cuidadosamente. Encontramos mencionadas todas las que existen y muchas que han sido removidas de su sitio original pero que el autor recuerda desde su niñez e irónicamente se pregunta dónde pueden estar. Al hablarnos de pintura, destaca de manera especial la obra de Antonio de Torres de quien no se conocía la importancia que tuvo en esa capital minera: "Pintor -dice- que llenó toda una etapa pictórica en San Francisco de San Luis Potosí." "Nació en México en 1666. Casó en 1693. Fue terciario franciscano." "Fue de los que cuidaron los fondos y las partes laterales decorativas de sus cuadros." 9

Menciona también el nombre de un buen escultor potosino de mediados del siglo xIx, hasta ahora desconocido: don Sixto Muñoz ${ }^{10}$ y anota la presencia del maestro escultor queretano, Rojas, en relación con los colaterales de la iglesia del Carmen, que han desaparecido. ${ }^{11}$ Este dato es muy importante por las relaciones formales que existen entre ciertos retablos potosinos y algunos queretanos y para poder en el futuro, profundizar en ellas. En cuanto a los tesoros de arte que conserva la iglesia del Carmen, De la Maza enumera los lienzos firmados por Vallejo y nos descubre que dos pinturas que se habian considerado siempre como del pincel de Tresguerras, son de Rodriguez Alconedo. 12

En su libro sobre la ciudad de México en el siglo xvir nos enteramos de que Juan de Cepeda, autor del convento de San Bernardo, como ya consta en la mayoria de los libros especializados, tuvo como ayudante al cantero Nicolás Covarrubias. ${ }^{13}$ Otra novedad de sumo interés en esta misma obra son los nombres que da y las consideraciones que hace sobre el desarrollo de la forma cupular en la capital.

8 Ibidem, p. 50.

Ibidem, p. 46.

10 Ibidem. pp. 54-55.

11 Ibidem, p. 82.

12 Ibidem, pp. 82-83.

13 Francisco de la Maza, La ciudad de México en el siglo XVII, p. 5I. Fondo de Cultura Económica. México, 1968. 
Pronto -dice- comenzó la reacción contra los artesanados. En 1601, precisamente, se encomendó al arquitecto Alonso Pérez de Castañeda la construcción del citado Hospital de Jesús. El arquitecto no quiso seguir la costumbre general y dibujó la primera bóveda esférica, sobre pechinas, de la ciudad de México. Fue labor tan enjundiosa que se quedó a medias, pues no se terminó hasta 1665. El ejemplo cundio. El jesuita Juan López de Arbaiza, que desde 1598 habla construido bóvedas en Puebla, construyó la magna iglesia de San Pedro y San Pablo en 1603 -hoy Hemeroteca Nacional- con bóvedas caídas, y luego en Santiago Tlatelolco, en 1609, se vuelve a las pechinas, asi como en 1623 en San Jerónimo. El paso hacia la cúpula estaba dado. 14

No pretendo que en los párrafos precedentes hayan quedado registrados todos los datos de primer orden que Francisco de la Maza dejó apuntados en los seis escritos mencionados, pero cuando menos el lector tendrá una idea del tipo de informaciones que puede encontrar en ellos.

OPINIONES, CONCEPTOS E INFORMACIONES SOBRE DIVERSAS OBRAS

Y MONUMENTOS ARTÍsticos

Es del todo conveniente mencionar por lo menos algunas de las innumerables opiniones sobre materia de arte, que el maestro De la Maza emitió a lo largo de las obras que hemos revisado y que son el fruto de muchos años de investigación y de los dictados de su sensibilidad privilegiada. Gracias pues, a esa labor por él desarrollada, contamos con las siguientes informaciones:

Que la única silleria colonial y el único órgano barroco que hay en San Luis Potosi, se conservan en el coro del templo de San Francisco. ${ }^{15}$

Que "las cúpulas potosinas son únicas, sin antecedentes ni consecuente", porque las lineas divisorias de los gajos no cubren las aristas, sino los medios o centros de los mismos gajos, cosa que produce la ilusión óptica de que se rehunden en sus medios y resaltan en sus artistas. "El efecto es sorprendente y encantador -dice el maestro-, no se sabe dónde empezó esta peculiaridad si en esta cúpula de San Francisco o en la del Carmen que estaba terminada en 1760 , no sabemos si la de San Francisco es anterior o posterior a ésta." 16

14 Ibidem, p. 13.

$15 \mathrm{El}$ arte colonial en San Luis Polosi, p. 46.

16. Ibidem, p. 41. 
Que la portada lateral de la catedral potosina es anterior a la principal, por su composición tritóstila y que está relacionada formalmente con la portada de San Francisco, que hizo escuela. y fue casi copiada en la iglesia de Guadalupe en Zacatecas. ${ }^{17}$

Que la iglesia del Carmen es uno de los tres lugares -además del templo de San Pablo en la ciudad de México y el de Santa Fe en Nuevo México- que poseen retablos de piedra labrada 18 con estípites que parecen ser antecedentes de los queretanos.

Que en la iglesia de San Cristóbal lo más notable es una escultura neoclásica de este santo, que es la de mayor calidad artística en toda la ciudad. 19

Que fue en la sencilla capilla de San Sebastián donde se comenzaron a usar, en arquitectura religiosa, los arcos lobulados o angrelados, 20 que abundan por cierto, en la ciudad potosina.

Que las principales características de la arquitectura civil potosina deben buscarse en los vanos, las claves de los arcos, los patios porticados con esbeltos pilares y sobre todo en los preciosos balcones elemento potosino por excelencia- de repisas mixtilíneas, alabeadas. Las cariátides que algunos de ellos lucen como parte de su ornamentación fueron tomados de uno de los libros de Serlio, en su edición española traducida por Villalpando, publicada en 1552. ${ }^{21}$ Nos da como ejemplo máximo del palacio potosino la Real Caja, obra de Felipe Cleere.

Del arte zacatecano aprendimos la existencia de las bóvedas nervadas, que indican la persistencia del gótico hasta el siglo xvir, como las que ostentaba el ruinoso convento de San Francisco, las cuales deben considerarse como un caso único en el norte del pais. ${ }^{22}$

El análisis artístico-religioso de la catedral zacatecana es una de las grandes lecciones de arte barroco que Francisco de la Maza legó a la posteridad; una de sus más atinadas y preciosistas interpretaciones simbólicas. En síntesis concluye que la estructura temático-religiosa de la sensacional fachada es un homenaje a la Eucaristía "... poema de piedra a las misteriosas especies del pan y del vino..." 26

17 Ibidem, pp. $37-38$.

18 Ibidem, p. 83.

19 Ibidem, p. 68.

20 Ibidem, p. 64.

21 Ibidem, p. 25.

22 Francisco de la Maza, "El Arte en la Ciudad de Nuestra Señora de los Zacatecas". México en el Arte, núm. 7, p. 8. Méxjco. 1949.

23 Ibidem, p. 13. 
Muy afortunada fue la ciudad de Durango en que De la Maza se preocupara por estudiar su arte colonial. Ante todo quiso desterrar la idea que prevalecía acerca de la pobreza artística de las provincias norteñas. Para ello glosó una serie de textos antiguos en los que prueba que dicha ciudad, en la etapa virreinal, alcanzó un mérito arquitectónico que no supieron estimar los cronistas del pasado ni los habitantes del presente, salvo, claro está, honrosas excepciones. 24 "En el siglo xvin -nos dice el ilustre desaparecido en su monografia sobre San Luis Potosi- ya no se quería imitar en provincia lo que se hacia en la capital y asi, cada ciudad tuvo su arquitectura civil inconfundible." 25 Resultado de este criterio es haber señalado y valorado atinadamente las diferencias formales de la arquitectura civil durangueña, totalmente desconocida cuando apareció su libro “. ... un arco muy rebajado -diceal hablar de las puertas de las casas de cuyo centro cae una piña a modo de mocárabe mudéjar, unas impostas completamente inútiles se ven en muchas de ellas." Al lado de esos mocárabes aparecen inusitados copetes coronando las puertas y gruesas cornisas -ondulantes a vecesque se enroscan sobre los mismos extremos de las casas y que pueden encontrarse también en los patios. Algo de suma importancia fue señalar que todas estas formas típicas durangueñas, al lado de otras de menor importancia, pero pertenecientes a la etapa barroca, ejercieron gran influencia en la arquitectura neoclásica del lugar y en general a lo largo del siglo xux. Quizá como caso único - por lo que hasta ahora sabemossea Durango la ciudad en donde el barroco tuvo la fuerza para incrustarse, según las propias palabras de De la Maza, en la arquitectura académica. ${ }^{27}$

Una de las últimas y más importantes contribuciones para afinar nuestros conocimientos sobre la etapa churrigueresca se encuentra en su libro sobre dicha variedad barroca en la ciudad de México y consiste en la rectificación que hizo a la fecha que hasta hace poco se admitía para la aparición de los primeros estipites en el altar de los Reyes de la Catedral. Por mucho tiempo se habla aceptado el año de 1737 como fecha de terminación de dicho retablo y de ahí se hacia partir la reproducción de dicho apoyo. De la Maza, sospechando por varias razones formales que la fecha debía ser anterior, volvió a revisar el texto que,

24 La ciudad de Durango, pp. 8-10.

$20 \mathrm{El}$ arte colonial en San Luis Potosi, p. 19.

26 La ciudad de Durango, p. 8.

27 Ibidem. p. 8. 
respecto a la dedicación del retablo aparece en Las Gacetas, asf́ como la fecha de llegada a México de Jerónimo de Balbás y concluyó que "... el retablo de los Reyes fue terminado hacia 1725". ${ }^{23}$ Fácilmente se comprenderá la trascendencia de esta modificación cronológica para precisar el desarrollo de esta modalidad tan importante para el arte mexicano.

\section{RECTIFICACIONES}

Todo trabajo de investigación, como es sabido de sobra, está sujeto a rectificaciones. Así, no es de extrañar que me vea en la necesidad de hacer algunas observaciones con el fin de aclarar ciertos puntos confusos en los libros revisados, ya sea porque el paso del tiempo ha invalidado algunas afirmaciones o porque, simplemente. son errores en los que cayó el maestro como sucede a cualquier historiador.

Ante todo en su artículo sobre Zacatecas, al hablar del templo de San Agustín, dice que su bella fachada lateral “... se encuentra rota y obstruida". Esto era absolutamente cierto cuando De la Maza escribió esas páginas, pero ahora ya no, pues afortunadamente para México, la fachada ha sido espléndidamente restaurada, devolviéndole casi su original esplendor.

El tema religioso representado en esta fachada lateral de San Agustín, que se refiere al momento en que el santo escucha la voz de la Divinidad, ostenta en su altorrelieve una composición escenográfica, que a pesar de las libertades barrocas de la epoca resulta excepcionalmente audaz. Las mismas cualidades presenta la representación de San Lucas pintando a la Virgen en la fachada del templo de Guadalupe en Zacatecas y nos extraña que el maestro De la Maza, a pesar de mencionarlas como obras muy poco comunes, no haya hecho hincapié en esta calidad de teatralidad que es su más sobresaliente y significativo valor artístico, como creaciones de la gran libertad barroca de fines del siglo xviII.

En su monografia potosina el autor dedica buenos párrafos a la aparición de la columna salomónica ${ }^{20}$ remontándose hasta los fenicios para buscar su origen. Habla de la columna helicoidal -es decir, únicaque un sultán regaló al Papa y de la cual derivan las salomónicas berninescas que habian de popularizar el empleo de dicho apoyo. Esta infor-

28 El churrigueresco en la ciudad de Mexico, p. 8. Fondo de Cultura Económica, México. 1969.

29 El arte colonial en San Luis Potosi, pp. 41-43. 
mación está bastante atrasada, pues como queda demostrado en la tesis profesional de la señorita Faustina Torne Ruiz -titulada: Estudio sobre la columna salomónica. México, UNAM, 1970- hay varios estudios especializados donde se demuestra con bastante fundamento el origen helenístico de la columna salomónica y la existencia, no de una sola columna helicoidal en el Vaticano, sino de doce, que formaban el ciborio de la tumba de San Pedro.

Para terminar estas breves enmiendas a los magníficos trabajos de mi amigo y maestro, quiero añadir que, en mi opinión, es de lamentarse que faltara en todas las publicaciones que hemos mencionado, un comentario final de síntesis interpretativa. Un intento de situar cada una de esas variantes del barroco regional y capitalino -que él conoció y dio a conocer- dentro del panorama del barroco mexicano.

\section{EL EMPLEO DEL TÉRMINO CHURRIGUERESCO Y OTROS}

Es también pertinente considerar aqui el sentido con que De la Maza empleó ciertos términos que designan distintos tiempos o formas del barroco, porque no estamos de acuerdo con la implicación que le da a la palabra churrigueresco.

El término barroco salomónico por ejemplo, aparece empleado con toda precisión ya que su significado no deja lugar a dudas. Se refiere, como es sabido, a denominar las obras en donde aparece esa clase de apoyo helicoidal y es un término cuyo uso, el mismo De la Maza contribuyó a extender por su claridad. No está de más transcribir algunas frases que dedicó a la belleza salomónica: "Las columnas se recubren de pámpanos sabiamente entrelazados, sin recargamientos ni puro juego, como siempre creen observar los ignorantes del Barroco, sino en armonia de espacios y de curvas..." so El término tritóstilo figura asimismo usado con toda propiedad al referirse a las columnas cuyo fuste está dividido en tercios según ha sido aceptado por los especialistas mexicanos desde que lo acuñara el arquitecto Manuel González Galván.

En cambio encontramos una contradicción importante en cuanto a la aplicación del término churrigueresco. Para empezar el mismo De la Maza, perfectamente bien enterado de la historia de esta palabra y de las aplicaciones que se le habfan dado, aceptó la existencia de una modalidad churrigueresca, mexicana, como claramente queda dicho al

30 Ibidem, p. 36. 
referirse a la exuberante capilla de Aránzazu en San Luis Potosi a la cual considera "... uno de los alardes del churrigueresco mexicano". ${ }^{81}$ Aceptada la existencia de esta etapa, la identificó con el empleo de pilastras estípites, como lo prueba la siguiente frase que escribió en relación con la sacristía del templo potosino de San Francisco, de la cual afirma: "... es churrigueresca, es decir que sus apoyos son pilastras estípites". 82 Con este último sentido es como más se ha usado el término churrigueresco en los últimos años, y fue también el maestro De la Maza quien contribuyó mucho a vulgarizarlo pues su uso resultó aclaratorio. Sin embargo en su libro sobre el churrigueresco en la ciudad de México, publicado solamente tres meses después del estudio anterior, que vio la luz en el mes de septiembre, sorprende encontrar las frases siguientes:

Hay que aclarar que no sólo debe designarse como "churrigueresco" el barroco con estípites, sino a muchas o casi todas las obras con pilastras comunes muy ornamentadas y que corresponden en España de 1689 a 1730 y en México de 1725 a 1780 , más o menos, ya que uno sólo es el sentido o "voluntad de forma" que preside a esas obras. ¿Cómo no llamar churrigue. rescos, por ejemplo, al palacio del Conde de Heras -antiguo Express- y al palacio Moncada - conocido por "Palacio Iturbide" - con sus fachadas de filigrana de piedra, con la misma complicada labor de las tachadas y retablos de la época? Nosotros aquí sin embargo, sólo estudiamos al churrigueresco con estípites. 38

Fácilmente se comprenderá lo peligroso que serfa volver a ampliar la capacidad calificativa del término churrigueresco y aplicarlo de nuevo a los monumentos que no presenten estípites. Tal cosa nos llevarfa otra vez a caer dentro de la confusión que imperó desde que Manuel $G$. Revilla acuńó el término, hasta la época de don Manuel Toussaint, en que se agrupaban bajo esta denominación obras de muy distintas caracteristicas entre sf. Creemos que más vale limitar la capacidad del término, estrictamente a las obras que presenten el empleo de estípites. Sólo así podremos entendernos claramente y evitaremos futuros problemas de comprensión no sólo dentro de las etapas del barroco mexicano sino del barroco de todo el continente en general. Lo que no alcanzo a explicar es la contradicción en la que cayó De la Maza dentro de un lapso de tiempo tan breve, pues la riqueza ornamental que presentan

81 lbidem, p. 48.

32 Ibidem, p. 46.

$\$ 3$ El churrigueresco en la ciudad de México, pp. 12-13. 
los palacios de Moncada y Soto Heras no constituye un argumento de peso, para llamarlos churriguerescos.

En lo que estamos plenamente de acuerdo con él es en que "... el churrigueresco no es, propiamente un estilo arquitectónico. Es un estilo más bien, escultórico y decorativo..." 34

Hablando en un sentido estético puedo afirmar que Francisco de la Maza supo, mejor dicho, pudo, como pocos, entender, sentir, gozar y explicar el arte barroco, ya fuera salomónico o churrigueresco o de cualquier otra variedad. Entendió la importancia de la sensibilidad nativa como fundamento de la expresión del barroco mexicano. Muchas veces dijo en sus clases que el barroco es un arte al que hay que llegar por inmersión, destacando con esto los méritos sensoriales que reconoća en la naturaleza de este gran arte. Comprendió igualmente sus valores religiosos y sociales, pero nada como sus propias palabras para aquilatar su manera de sentir lo barroco. Los siguientes párrafos están dedicados a la Portada de los Arcángeles de la iglesia del Carmen, de su ciudad natal y en ellos dice: “... infinito vibrar de la más apretada y complicada elaboración de las formas, que van plasmándose en ordenadas y labradas estalactitas hasta lograr, incansable, el portentoso imafronte." "La portada de los Arcángeles es, además, la última obra de gran aliento barroco que se hizo en México." "Ante esta obra de arte imponderable, que no es escenografía ni retórica, como quieren encontrar en todo barroco algunos críticos sedicentes, que tampoco es mística ni sutileza espiritual, sino encanto de los sentidos y glorificación de la forma, lo único que se impone es el silencio porque la palabra, a menos que fuera poética, altamente poética, no puede competir con la absorción en que se suspende el alma de quienes saben admirar. $Y$ 'la admiración -dijo Aristóteles- es la más profunda de las actitudes humanas." 35

\section{La PREOcupación POR LA SALVAción DEL ARTE colonial}

Quien quiera que lea los libros de arte mencionados en estas notas, se dará cuenta de que las obras de Francisco de la Maza no son solamente informativas, sino que además de ello tratan de que la obra de arte se comprenda como el genuino e insustituible producto del alma

34 Ibidem, p. 13.

35 El arte colonial en San Luis Potosi, pp. 84-85. 
humana. El valor histórico de las obras de arte se encuentra puesto de relieve en sus escritos por medio de las informaciones -a veces muy amplias y detalladas- que proporciona sobre las vidas y acciones de los patronos constructores, sobre las anécdotas de las órdenes religiosas, sobre las actitudes clericales, en fin sobre todos los actos humanos que motivaron la construcción de un monumento. Si el arte se acepta así, como la creación peculiar de cada época histórica, resalta de inmediato la importancia de su indispensabilidad para la vida de la sociedad moderna. Así, el arte colonial, expresión peculiar del hombre novohispano, parte importantísima de nuestra herencia cultural, reflejo de sus anhelos, riquezas, creencias, etcétera, debe respetarse y conservarse con la seguridad de que las obras que se dañen o se destruyan jamás serán sustituidas. De la Maza, con esta conciencia de las cosas, se convirtió muy pronto en uno de los apóstoles defensores del arte colonial, tan atacado por diversas vicisitudes históricas.

Por eso nos dice con molestia en alguna parte de sus libros: “... una ciudad no es un desenvolvimiento puramente racional y lógico, sino humano, efectivo, cordial, variable, con sentido más allá de lo comercial y con necesidades sociales, religiosas y estéticas -y más adelante añade-: Una ciudad vieja es ya así y es intocable en su trazo fundamental. A quien no le guste, que viva fuera de ella. Y lo peor es hacer 'remiendos' que de nada sirven, como lo ha experimentado la ciudad de México." 36 Este apostolado lo ejerció Francisco de la Maza hasta en sus libros, pues en las obras que he reseñado, aparte de ofrecer al lector toda la información histórica y formal acerca de los monumentos que trata, hace una angustiosa llamada para que las personas y las ciudades tomen conciencia del valor del arte colonial y conserven y restauren lo que esté deteriorado; alarmado ante el desprecio que la época actual ha mostrado por su patrimonio artístico, destruyendo no sólo obras aisladas sino la belleza urbanística de ciudades enteras. Así, muchos de sus párrafos se vuelven evocativos y tristes, por ejemplo cuando habla de la perdida hermosura de la ciudad de México: "Fue entonces México, una ciudad en rojo y blanco [se refiere al empleo del tezontle y la chiluca] bicromía preciosa y rara, que empezó a perderse con el neoclásico al usar solo cantera." 37

De la Maza, indudablemente, quiso conmover a sus lectores, inclinarlos a favor del arte colonial, explicárselos ponderando su belleza y

30 Ibidem, pp. 16-17.

87 La ciudad de Mexico en el siglo XFII, p. 14 
explayándose en largos párrafos en contra de los destructores de su ciudad natal: “... los hombres del siglo pasado -dice- creyeron que abrir calles o prolongarlas, era el 'progreso' (?). Asi cayó también la iglesia de Tequisquiapan que cerraba la ciudad por el poniente. $Y$ esa pobre y fácil urbanística, la del derrumbe de iglesias y casas, para 'abrir' perspectivas, fue la ley decimonónica ... continuada por los 'modernos' del siglo $\mathrm{xx}$, que siempre creen que están haciendo algo original, nuevo y útil." Cuando nota que sus lamentaciones son ya muy repetidas, aclara que "... no sólo es un deplorar lo irremediable, sino un tratar de prevenir lo futurible..." 38 Pero como sobran motivos de queja, vuelve a insistir sobre el tema: "Malos tiempos eran para el Arte Colo nial de México esos del porfirismo, más 'progresista' y destructor que la Reforma o la Revolución en este aspecto del sistemático derrumbe de edificios antiguos, como si no hubiera otro sitio donde colocar los edificios modernos. Pero... igual cosa sucede ahora, año de 1969." 39

Por las mismas razones estéticas e históricas, De la Maza se declaró siempre a favor de la restauración de las obras respetando los originales y condenando siempre las "invenciones" para completar una obra mutilada o sustituir una desaparecida. A propósito de eso nos dice:

Pero si fue abominable y aun pecaminoso destruir los retablos barrocos, más aún lo es inventarlos ahora y "crear" con formas ya exhaustas, nuevos altares antiguos. No es el caso, bien hecho en si, de reconstruir, con base documental cierta lo que antes hubo, como en el caso de San Francisco en la ciudad de México, que se volvió a erigir el retablo mayor con el mismo y original proyecto que dibujó Jerónimo Antonio Gil, o en San Fernando, de la misma ciudad, en donde, siguiendo una afortunada litografia, se ha reconstruido el altar mayor churrigueresco. Lo más abominable y pecaminoso es, como deciamos, inventar en donde absolutamente no sabemos to que hubo. Tal es el ejemplo, "Fabio |Ay! dolor", en los cruceros y en el presbiterio de nuestro San Francisco Potosino. Más valia la "mustia soledad" de las paredes vaclas. 10

Francisco de la Maza, como lo demuestra toda su obra escrita y los testimonios de todos nosotros sus amigos, discipulos, colegas y contem. poráneos en general, luchó a brazo partido por la conservación y restauración de nuestro patrimonio artistico novohispano. Esta lucha tan desigualmente sostenida contra muchos particulares y las propias autori-

88 El arte colonial en San Luis Potosi, p. 59.

30 Ibidem, p. 61.

10 Ibidem, p. 44. 
dades civiles y eclesiásticas es un gran mérito en su obra, tan importante como su calidad académica.

El espiritu de lucha que informa estos estudios les comunica, muchas veces, un tono trágico irritante, como cuando nos dice: "Todo lo que el clero colonial creó y conservó con entusiasmo y respeto, el ignorante clero de los siglos xix y $\mathrm{xx}$ desplaza y destruye a su capricho." 11

El gran maestro defensor del arte colonial murió, desgraciadamente, con una triste sensación de impotencia al respecto, pero estoy segura que una de las cosas que más le hubiesen agradado, hubiera sido la proclamación de ésta su esforzada, mantenida y meritoria lucha por el arte.

Queden pues, estas líneas, aunque insuficientemente elocuentes, como testimonio de la validez de las razones que motivaron su lucha y como votos porque su actitud encuentre pronto eco en las conciencias de los mexicanos.

41 Ibidem, p. 50. 